\title{
PESQUISA CIENTÍFICA EM MARKETING DE SERVIÇOS NO BRASIL
}

\section{SERVICES MARKETING SCIENTIFIC RESEARCH IN BRAZIL}

Marcio Oliveira Mota

Professor Efetivo e membro do corpo permanente do mestrado acadêmico - Universidade Estadual do

Ceará

Fortaleza, CE, Brasil

E-mail: marcio@marciomota.com

Ana Augusta Ferreira Freitas

Professora Titular e membro do corpo permanente do mestrado acadêmico - Universidade Estadual do

Ceará

Fortaleza, CE, Brasil

E-mail: freitas8@terra.com.br

Felipe Gerhard

Mestrando na Universidade Estadual do Ceará

Fortaleza, CE, Brasil

E-mail: felipegerhard@yahoo.com.br

Simony Rodrigues Marins

Mestranda na Universidade Estadual do Ceará

Fortaleza, CE, Brasil

E-mail: simonymarins@gmail.com

Lucas Lopes Ferreira de Souza

Mestrando na Universidade Estadual do Ceará

Fortaleza, CE, Brasil

E-mail: lucaslfsouza@hotmail.com

\section{RESUMO}

Este estudo objetiva investigar a produção no campo de marketing de serviços no Brasil. Para isto foi realizado um estudo exploratório de caráter qualitativo e quantitativo por meio de um levantamento bibliométrico. Foram analisados 206 artigos publicados nos congressos EnANPAD e EMA e em periódicos A2 e B1 Qualis/Capes nacionais no ano de 2013. Os objetivos específicos são: 1) levantar a evolução histórica do marketing de serviços no Brasil, por meio da análise dos principais artigos produzidos, de maneira a erigir o estado da arte do tema; 2) identificar as principais categorias teóricas pesquisadas e; 3) sugerir tendências de estudo à área com base na produtividade nacional, observando-se, igualmente, o contexto internacional. Dentre os achados destacam-se: baixa originalidade dos estudos nacionais, ausência de posicionamento teórico nos trabalhos, declínio da produção acadêmica e forte ligação entre marketing de serviços $\mathrm{e}$ áreas de marketing de relacionamento $\mathrm{e}$ comportamento do consumidor. Ao final, são observadas tendências para pesquisas futuras.

Palavras-chave: Marketing de serviços. Pesquisa bibliométrica. Produção nacional. Tendências. Brasil.

Data de submissão: 14 de março de 2015.

\section{ABSTRACT}

This study aims to investigate the pattern of publications of services marketing in Brazil. An exploratory qualitative and quantitative research was carried out through appropriate bibliometric measures. We analysed 206 papers published on EnANPAD and EMA conferences and on A2 and B1 Qualis/Capes Brazilian journals since 1965. The specific objectives are to: 1) present the historical evolution of the field of services marketing through the analysis of the most prestigious journals in Brazil in order to bring up the state of art; 2) identify the main theoretical categories of Services Marketing; and 3) suggest trends to this body of literature in Brazil in comparison to the international context. Given the above shortcomings, we highlight the low originality of the Brazilian studies, the lack of theoretical positioning, a decline of the number of papers in the field and high bonds between relationship marketing and consumer behavior. Moreover, we present theoretical trends in order to contribute towards future researches.

Keywords: Services marketing. Bibliometric study. Number of national papers. Tendencies. Brazil.

Data de aprovação: 27 de março de 2017. 


\section{INTRODUÇÃO}

O escopo do marketing ampliou-se para abranger, além da tradicional comercialização de bens tangíveis, a comercialização de bens intangíveis. Nessa conjectura se inseriu a importância do marketing de serviços no processo de construção teórica e paradigmática do marketing (VARGO; LUSCH, 2004). Segundo Berry e Parasuraman (1993), as sementes do campo de marketing de serviços foram plantadas na década de 1960 nos Estados Unidos. Contudo, somente germinariam a partir dos anos de 1970, devido à destacada contribuição de diversas Instituições de Ensino, associações, periódicos e, em especial, de autores que erigiram as bases teóricas do novo campo de estudo. Desde então, pesquisas concernentes ao tema, realizadas principalmente nos Estados Unidos e na Europa, se multiplicaram e o elevaram à categoria de subdisciplina do marketing.

Não obstante, os estudos em marketing de serviços no Brasil apresentam algumas peculiaridades. Embora a disciplina tenha ganhado notoriedade acadêmica ao longo dos últimos anos, não há uma análise sistêmica da evolução teórica da área, bem como o levantamento do atual estado da arte no país. Um estudo de caráter seminal foi desenvolvido por Rocha e Silva (2006), contudo foram levantados somente os trabalhos publicados nos anais do EnAnpad, em um total de 50 estudos. Igualmente, Mondo e Fiates (2013) e Castro et al. (2013) realizaram estudos bibliométricos em marketing de serviços, no entanto, o primeiro com foco somente na variável qualidade e o segundo fazendo um levantamento de estudos internacionais.

Dessa forma, o presente estudo tem por objetivo investigar a produção no campo de marketing de serviços no Brasil. Para tanto, foram levantados todos os artigos que se inserem no escopo da disciplina, desde o surgimento dos primeiros trabalhos direcionados à temática, que remontam à década de 1960, até dezembro de 2013. Dentre os objetivos específicos estão: 1) levantar a evolução histórica da subdisciplina no Brasil, através da análise dos principais artigos produzidos, de maneira a erigir o estado da arte do tema; 2) identificar as principais categorias teóricas pesquisadas e 3) sugerir tendências de estudo à área com base na produção nacional, observando-se, igualmente, o contexto internacional.

Para o alcance destes objetivos, foi realizado um estudo exploratório de caráter qualitativo e quantitativo, através de um levantamento bibliométrico. Foram analisados os artigos publicados no Encontro da ANPAD (EnANPAD), no Encontro de Marketing da ANPAD (EMA) e em periódicos A2 e B1 nacionais conceituados pelo sistema Qualis da Capes no ano de 2013, totalizando 206 estudos. Cumpre salientar, contudo, que diversos artigos, apesar de realizarem pesquisas em empresas do setor de serviços, não foram incluídos na análise, pois possuíam área de concentração distinta da estudada pelo marketing de serviços.

$\mathrm{O}$ artigo estrutura-se em quatro etapas, além desta introdução. Em primeiro lugar, serão analisados os principais fatores concernentes à teoria do marketing de serviços. Em seguida serão tratados os principais aspectos metodológicos da pesquisa: perscrutar-se-á a trajetória da área e os principais artigos publicados; categorizar-se-ão todos os trabalhos de acordo com suas unidades de estudo; avaliar-se-ão quantitativamente as publicações; examinar-se-ão suas propriedades metodológicas; analisar-se-ão criticamente as obras; e delinear-se-ão tendências à disciplina. Logo após, serão realizadas as análises e discussões referentes à produção do campo de estudo no Brasil. Por fim, serão evidenciadas as considerações finais do trabalho. 


\section{MARKETING DE SERVIÇOS}

O marketing de serviços emerge em um contexto no qual o marketing estava voltado somente para o produto, quando a visão tradicional, baseada nos 4Ps, era vigente (LOVELOCK, 1983; VARGO; LUSCH, 2004). Gummesson e Grönroos (2012) mostram a evolução do marketing de serviços a partir de três paradigmas: o paradigma de bens (até 1970); o paradigma que se focava na diferença entre bens e serviços (de 1970 a 2000); e o paradigma baseado na integração e interdependência de bens e serviços (desde os anos 2000). A partir desses fatores, ressalta-se a importância de estudar essa nova subdisciplina do marketing.

Dentre os autores que se destacaram como pioneiros na diferenciação entre marketing tradicional e de serviços, destaca-se Shostack (1977), que enfatizou a necessidade de criação de novos conceitos para que a área fosse bem-sucedida. $O$ trabalho da autora marcou o início de um rápido e profundo período de reflexões internacionais. A área de marketing de serviços surge com o intuito de englobar o setor de serviços e os seus fatores intangíveis, visando principalmente o exame da qualidade nesses ambientes (BERRY; PARASURAMAN, 1993; GROVE; FISK; JOHN, 2003). Gummesson e Grönroos (2012) definiram marketing de serviços como um conceito que inclui o desempenho da firma na proposição de valor, além da dissolução da divisão entre bens e serviços. Dentre outros conceitos que vêm emergindo, os mais interessantes são o de cocriação de valor e serviço e o de integração de recursos entre stakeholders, dando um papel ativo aos clientes.

Bateson (1978) desenvolveu uma das classificações mais utilizadas para o enquadramento das características de serviços, ao proclamar seus aspectos de inseparabilidade, intangibilidade, heterogeneidade e perecibilidade, em confronto com as características relacionadas aos bens. Com Booms e Bitner (1981), por exemplo, o mix do marketing de serviços passa a inserir os chamados 7 Ps: elementos do produto; praça ou localização; promoção; preço; processo; pessoas e ambiente físico (em inglês physical evidence).

Lovelock (1983) amplia a complexidade teórica do campo ao definir cinco grupos para classificar os serviços, cada qual com estratégias específicas, embora não excludentes, para seu tratamento, a saber: 1) a natureza da ação de serviços; 2) o tipo de relacionamento entre prestadores e clientes; 3) o grau de customização e personalização destes serviços; 4) a natureza da procura em relação à oferta (sazonalidade); e 5) a demanda e formas de entrega. De forma análoga, Bowen (1990) cria uma taxonomia parecida com a de Lovelock (1983) quanto ao grau de customização: a) alto contato e serviços personalizados (e.g. hotel, restaurantes), b) contato moderado e serviços semipersonalizados (e.g. agências de viagens); e c) contato moderado e serviços padronizados (e.g. restaurantes fast food, bancos).

Além das características supracitadas, o marketing de serviços apresenta peculiaridades destinadas ao seu ambiente de aplicação e à experiência na troca entre provedores e clientes. Bitner (1992) aborda o conceito de ambiente de serviços (servicescapes) e indica como fatores ambientais: condições relacionadas aos sentidos humanos (temperatura, cheiro etc.), especificações (layout) e significados simbólicos do espaço (estilo, decoração), que afetam o comportamento tanto de clientes quanto de vendedores, provocando-lhes atitudes de afastamento ou aproximação entre suas interações. Tais interações são aprofundadas por Groove e Fisk (1992) quando propõem um modelo teórico que metaforiza a experiência em trocas de serviços como uma peça dramatúrgica teatral, analisando o local onde os serviços ocorrem e as relações ali desenvolvidas. 
Para os autores, os personagens são os clientes e os prestadores, o ambiente um palco e o desempenho uma atuação.

Da mesma forma, a qualidade de serviços possui atenção destacada na área desde que Parasuraman, Zeithaml e Berry (1985) definiram os critérios para uma das escalas mais conhecidas e replicadas no marketing, a SERVQUAL; escala que mensura a qualidade incorrida em um contexto de prestação de serviço, ao tratar dos construtos tangibilidade, confiabilidade, responsividade, segurança e empatia (PARASURAMAN; ZEITHAML; BERRY, 1988). Em diversos estudos, a escala vem associada a construtos que se tornaram fundamentais no contexto do marketing, como confiança, satisfação, comprometimento e lealdade, tipicamente evidenciados no campo do marketing de relacionamento e do comportamento do consumidor.

Aspectos referentes aos pontos negativos na prestação de serviços passaram a ser notadamente aprofundados após a explanação de autores como Cronin (2003) e Kunz e Hogreve (2011), que observaram a necessidade de recuperação em falhas de serviços, bem como aspectos referentes ao comportamento do consumidor que interferem na prestação e qualidade dos serviços, como a insatisfação, a reclamação, emoções de raiva e percepção de injustiça.

Os fatores anteriores evidenciam mudanças contextuais e teóricas que, de forma concomitante, vêm a fortalecer as peculiaridades referentes ao marketing de serviços. Recentemente, reflexões acadêmicas têm elencado a possibilidade de uma nova lógica dominante em marketing, a chamada Lógica Dominante de Serviços (Service Dominant Logic), sendo os estudos de Vargo e Lusch (2004) os promotores desta visão. Tal lógica gera repercussões diferenciadas nas estratégias e ações de marketing. Os autores argumentam que novas perspectivas têm focado em recursos intangíveis, na cocriação de valor e em relacionamentos, ressaltando que a provisão de serviços seria mais importante do que a de produtos nas trocas econômicas. Estes fatores, além de ampliarem o escopo e a abrangência da definição de serviços, podem provocar novas maneiras de apreensão da realidade do marketing, e em particular a de serviços.

\section{METODOLOGIA}

A revisão da literatura seguiu o método proposto por Villas, Macedo-Soares e Russo (2008). As investigações bibliográficas foram iniciadas com uma análise do ranking dos periódicos e dos eventos científicos mais importantes da área. Logo após, foram selecionados os artigos através de uma busca utilizando-se palavras-chave em cada edição dos periódicos e dos anais dos eventos. Em seguida, foram analisados todos os artigos por completo, observando-se os principais itens que os compõem. O método de análise divide-se em quatro partes, detalhadas a seguir.

\section{Seleção dos periódicos}

Foram selecionados os principais periódicos nacionais, com conceito $\mathrm{A} 2$ ou $\mathrm{B} 1$, que possuíssem o marketing como área de concentração, no sistema de qualificação de periódicos Qualis no ano de 2013. Da mesma forma, foram selecionados os principais congressos nacionais em Administração e Marketing: Encontro da Associação Nacional de Pós-Graduação e Pesquisa em Administração (EnANPAD) e Estudos 
em Marketing da ANPAD (EMA). Este último evento também foi revisado por ser voltado integralmente ao marketing. Foram levantados artigos de edições desde os anos de 1960. Contudo, cabe salientar que diversos artigos publicados em periódicos foram inicialmente apresentados em eventos. Privilegiaram-se, nesta análise, os trabalhos publicados em periódicos.

\section{Identificação dos artigos}

Depois de selecionados os periódicos e eventos, foram identificados os artigos pertinentes à disciplina de marketing de serviços. A pesquisa foi realizada utilizando-se as palavras-chave marketing de serviços, marketing e serviços em cada edição dos periódicos e dos anais dos eventos desde que foram criados. Ao final, 206 artigos foram selecionados. Cumpre observar que foram inseridas na análise pesquisas que, embora não se valessem do arcabouço teórico do marketing de serviços, trouxeram alguma contribuição à área.

\section{Classificação dos artigos e análise da base de dados}

Para a criação de uma base de dados, cada artigo foi classificado de acordo com o título, autor, nome do periódico, ano da publicação, palavras-chave, citações, lacunas teóricas, estrutura do referencial teórico, aspectos metodológicos, limitações, perspectivas de pesquisa e implicações gerenciais e acadêmicas. Quanto aos aspectos metodológicos, foram observados: o tipo de pesquisa, se quantitativo, qualitativo ou qualitativo-quantitativo; as técnicas de coleta de dados empíricos (GODOI; BALSINI, 2006); e níveis de pesquisa, se descritivo, exploratório ou experimental (GIL, 1989). Observando-se a inexistência de categorização metodológica em alguns artigos, foram realizadas a identificação e a classificação segundo Godoi e Balsini (2006) e Gil (1989). Subsequentemente, os artigos foram classificados em grandes categorias dentro do campo de marketing de serviços através da leitura do artigo por completo, observando-se a unidade de estudo de cada pesquisa.

\section{Análise em profundidade}

Os artigos foram inicialmente agrupados e analisados de acordo com a década de publicação: antes da década de 1990; década de 1990; e após os anos 2000. Em seguida foram analisados itens como: temática, caráter (qualitativo ou quantitativo), perspectiva de pesquisa (descritiva, exploratória ou experimental), unidade de estudo, setores de estudo, autores, citações, objetivos, lacunas, limitações, sugestões para pesquisas futuras e implicações gerenciais e acadêmicas. Logo após, foram criadas grandes categorias de pesquisas, observando-se as unidades de estudo dos artigos. Por fim, foi analisada a estrutura teórica do marketing de serviços no Brasil, auferindo-se, principalmente, a coerência teórica e as perspectivas e tendências do campo de estudo. 


\section{ANÁLISES E DISCUSSÕES}

Nesta seção, serão realizadas as análises e discussões referentes à produção em marketing de serviços no Brasil. Para tal, será traçada inicialmente a evolução do campo de estudo. Em seguida, serão categorizados todos os trabalhos de acordo com suas unidades de estudo. As publicações serão, por conseguinte, avaliadas quantitativamente, observando-se suas propriedades metodológicas. Por fim, será realizada uma análise crítica dos artigos e delineadas as tendências à disciplina.

\section{Evolução do Marketing de Serviços no Brasil}

Para a análise da trajetória e dos principais artigos publicados na área de marketing de serviços, segmentou-se a série histórica de produções científicas, devido às particularidades apresentadas pelos trabalhos em cada estrato, em três períodos, a saber: antes da década de 1990; década de 1990; e após os anos 2000.

Antes da década de 1990

O primeiro autor a tratar especificamente sobre serviços no Brasil remonta à década de 1960. Lima Filho (1965) foi o precursor no estudo sobre a temática, embora ainda inexistente a disciplina ou mesmo a expressão marketing de serviços. Na ocasião, o autor analisou a situação mercadológica dos serviços no país, comparando o grau de utilização de diferentes espécies de serviços (serviços em geral; serviços que acompanham produtos; produção terciária e mercadização comparada) no Brasil e nos Estados Unidos. Outros artigos referindo-se ao tema somente seriam produzidos décadas depois.

$\mathrm{Na}$ década de 1980, observa-se claramente a importância da disseminação da tecnologia computacional no ambiente empresarial e, mais especificamente, no desempenho dos serviços oferecidos através do estudo de Rodrigues et al. (1984). Os autores expõem o receio advindo da inserção da microtecnologia no ambiente organizacional. A medida que observam o processo de automação do setor de serviços, os pesquisadores permitem que se visualize como se estruturavam as relações sociais e organizacionais da época. Os autores analisaram as mudanças estruturais na organização do trabalho advindas da introdução do computador, uma vez que este veio a modificar por completo o desempenho das atividades centrais da empresa, como o atendimento ao cliente.

Figueiredo (1989), contudo, foi o primeiro autor a abordar os construtos da disciplina e a citar a expressão marketing de serviços no contexto brasileiro. No trabalho, o autor salienta a necessidade de uma interação harmônica entre os setores de marketing e produção em empresas de serviços, classificando as características de serviços e relacionando-as à existência de conflitos entre as duas áreas. Embora a pesquisa tenha sido realizada em empresas espanholas, ressalta-se a importância do artigo tanto no esforço de se introduzir a temática no contexto acadêmico brasileiro, quanto em destacar a relevância de uma administração profissional voltada ao setor de serviços no país.

No contexto internacional, Berry e Parasuraman (1993) apontam o trabalho desenvolvido por Shostack (1977) como o primeiro a contribuir substancialmente à legitimação do marketing de serviços como 
campo de pesquisa. Contudo, a sedimentação do conhecimento na área só viria a ocorrer anos depois. Competindo para a aceleração desse fenômeno, estão os estudos desenvolvidos, principalmente, por Christopher Lovelock, Evert Gummesson, Parasuraman, Valarie Zeithaml, Leonard Berry e Christian Grönroos. Da mesma forma, a American Marketing Association (AMA) realizou a primeira conferência em marketing de serviços somente em 1981 (BERRY; PARASURAMAN, 1993). Destarte, observa-se nos artigos produzidos no Brasil, até a década de 1990, a inexistência de teorias relacionadas ao marketing de serviços, uma vez que a disciplina ainda não estava cristalizada ao ponto de permitir maiores contribuições aos pesquisadores.

Década de 1990

Os primeiros artigos do período foram publicados a partir da segunda metade da década de 1990 . Abreu (1996) inicia o período fazendo uma crítica teórica ao chamado marketing tradicional. Objetivando ampliar seu escopo, a autora sugere a inserção do serviço de pós-venda na disciplina de marketing. Sua crítica residia na inobservância do serviço pós-venda pela maioria das organizações brasileiras da época, as quais se restringiam à prestação de serviços de pré e de venda; o que, em sua visão, negligenciava uma das etapas mais importantes e decisivas para a imagem da empresa no mercado: o marketing aftersale, conforme expressão da autora. Referenciando estudos de sumidades do marketing de serviços, construtos como a satisfação e a lealdade dos clientes são analisados no trabalho. O vazio teórico e empírico sobre a questão foi sentido pela autora na sustentação da problemática colocada. Como sugestões de pesquisa, ademais, ela apontou o marketing de relacionamento, centrado nos serviços pós-venda.

Com a expansão e consolidação do EnANPAD, houve uma ampliação considerável do número de artigos sobre marketing de serviços produzidos na década, o que contribuiu diretamente para a disseminação da temática no Brasil. Dentre os trabalhos mais importantes do congresso nesse período, destaca-se o de Urdan (1997), por ser um dos primeiros a tratar especificamente da qualidade de serviços, um dos construtos seminais à construção do arcabouço teórico na área. Replicando o trabalho de expoentes do marketing de serviços internacional (e.g., PARASURAMAN; ZEITHAML; BERRY, 1985), o autor testa empiricamente a existência de uma relação linear positiva entre as lacunas de qualidade percebida, externa, e do marketing, interno.

Contudo, somente com o trabalho realizado por Arruda e Arruda (1998) é que o termo marketing de serviços veio a ser novamente mencionado; expressão utilizada primeiramente por Figueiredo (1989). O artigo insere-se especificamente na linha teórica da disciplina, uma vez que, realizando levantamentos em grandes companhias aéreas da época, os autores analisaram a qualidade dos serviços prestados como antecedente da satisfação; utilizando para tal um modelo para mensuração da satisfação do consumidor sugerido por autores internacionais. A maior contribuição do trabalho, contudo, foi a de demonstrar aos acadêmicos de marketing nacionais a existência de uma teoria voltada unicamente à área de serviços.

De forma geral, os artigos publicados na década possuem caráter descritivo, com perspectiva quantitativa. Os estudos empíricos predominam dentre os trabalhos realizados, sendo viabilizados, na grande maioria dos casos, por levantamentos. Quanto às limitações e sugestões para trabalhos futuros apresentados, observa-se que alguns autores, quando utilizavam técnicas de pesquisa quantitativas, sugeriam que fossem 
utilizados métodos qualitativos. Da mesma forma, quando os trabalhos possuíam perspectivas qualitativas eram sugeridas melhorias metodológicas no que tange à busca de generalização dos dados, utilizando-se, para tal, técnicas quantitativas. No que concerne às lacunas teóricas apontadas pelos autores, observou-se que, em geral, houve pouca clareza ao evidenciá-las ou não foram explicitados os aspectos de continuidade de pesquisas anteriores. Outrossim, a carência de estudos prévios na área foi a principal razão pela qual os autores demonstram a importância da realização de seus trabalhos.

Após os anos 2000

No início dos anos 2000, destaca-se o artigo de Veiga, Gonçalves e Moura (2002), apresentado no EnANPAD; por ser o primeiro do evento a tratar, no contexto brasileiro, da escala SERVQUAL, de autoria de Parasuraman, Zeithaml e Berry (1988). O trabalho realizado pelos autores objetivou a validação da escala de mensuração da qualidade observando as peculiaridades inerentes à cultura local. Da mesma forma, salientase o estudo realizado por Dutra, Oliveira e Gouveia (2002) por ser o primeiro do evento a avaliar a qualidade de um serviço através da escala SERVQUAL.

Outro importante estudo cujo enfoque recai sobre construtos na área de marketing de serviços foi realizado por Brasil (2002). No artigo, o autor realiza uma ampla revisão da literatura internacional de marketing de serviços, ressaltando a importância do servicescape - conceito proposto por Bitner (1992), que associa a atmosfera de serviços ao papel desempenhado pelos funcionários, pelo ambiente físico e pelos próprios clientes - e das características pré-compra, compra-consumo e pós-compra no marketing de serviços.

Igualmente, outro trabalho a destacar-se em âmbito nacional por embasar-se em artigos seminais do marketing de serviços foi realizado por Dias (2006). A autora contribuiu para uma reflexão sobre a formação, geração e evolução do conhecimento em marketing, ao realizar uma análise crítica da proposição de Vargo e Lusch (2004) sobre a nova lógica do marketing; pautada em serviços e centrada em recursos intangíveis, cocriação de valor e relacionamento.

Embora em âmbito internacional viessem ganhando destaque artigos que abordam contextos de serviços atuais, como é o caso dos serviços online, essa seara ainda não possuía uma quantidade de pesquisas significativas no Brasil à época. Dentre os poucos pesquisadores nacionais a abordarem o tema destaca-se Brei (2003), pioneiro em estudos na temática. Em sua obra, o autor desenvolve um modelo teórico que descreve como se constrói a confiança do cliente usuário de internet em trocas relacionais de serviço. Outro importante trabalho foi desenvolvido por Vieira (2010). O autor, além de verificar a escala de qualidade eletrônica e-S-QUAL, de Parasuraman, Zeithaml e Malhotra (2005), testa um modelo que avalia as relações entre qualidade percebida pelo cliente do varejo virtual e os construtos de comprometimento, lealdade e confiança. 


\section{Categorias gerais encontradas}

Após análise das unidades de estudo dos artigos levantados, os resultados foram resumidos no Quadro 1, a seguir. Foram estabelecidas dez grandes áreas, que contribuem para o escopo teórico do marketing de serviços, quais sejam: Ambiente de Serviço, Marketing de Relacionamento, Encontro de Serviços, Comportamento Pós-compra de Serviços, Aspectos Cognitivos, Atributos ou Propriedades de Serviços, Imagem da Marca, Lógica Dominante de Serviços e Gerenciamento (categoria com maior intercâmbio com áreas gerenciais da empresa).

\section{Quadro 1-Grandes categorias observadas}

\begin{tabular}{|c|}
\hline Construtos/Variáveis (quantidade) \\
\hline Ambiente de serviço \\
\hline $\begin{array}{c}\text { Ambiente (Cenário) de serviço (16); Contato com o cliente (12); Imagem/Impressões do serviço (10); Música (1). } \\
\text { Iluminação (3) }\end{array}$ \\
\hline Marketing de Relacionamento \\
\hline $\begin{array}{l}\text { Benefícios relacionais (2); Dissolução de relacionamento (1); Intenção de recompra (2); Natureza relacional do serviço } \\
\text { (14); Retenção de clientes (8); Co-criação (2); Serviço Pós-vendas (1) }\end{array}$ \\
\hline Encontro de Serviços \\
\hline Encontro de serviços/Hora da verdade (4); Experiência de consumo (2); Experiência de serviço (1) \\
\hline Comportamento Pós-Compra de Serviços \\
\hline $\begin{array}{l}\text { Boca a boca (7); Comprometimento (5); Confiança (16); Fidelidade (6); Justiça (5); Lealdade (25); Percepção (6); } \\
\text { Qualidade (78); Qualidade de marketing (1); Risco percebido (4); Risco social percebido (1); Custo de mudança (1); } \\
\text { Satisfação (70); Valor percebido (22) }\end{array}$ \\
\hline Atributos de Serviços \\
\hline $\begin{array}{c}\text { Importância/Excelência do serviço (2); Intensidade de serviço (1); Sequência de serviço (2); Serviço agregado (1); Mix } \\
\text { de serviços/Mix de marketing (3); Falha no serviço (7); Recuperação de serviço (9); Atendimento de reclamações (5); } \\
\text { Autosserviço/Autoatendimento (2); Atributos percebidos (7); Categorização de serviços (4); Customização (2); Tempo } \\
\text { de entrega (2); Tempo de espera (1) }\end{array}$ \\
\hline Aspectos Cognitivos \\
\hline $\begin{array}{c}\text { Expectativa (13); Experiências emocionais/Emoções (9); Humor (1); Motivação (1); Influências hedônicas (2); } \\
\text { Resposta afetiva (1); Sacrifício (1); Aspectos cognitivos pessoais (2); Intenção de troca (1); Decisão de compra (9); } \\
\text { Tolerância (2) }\end{array}$ \\
\hline Imagem da Marca \\
\hline Extensões de marca (2); Marca (3); Similaridade de marca (1); Reputação (3) \\
\hline Lógica Dominante de Serviços \\
\hline Nova lógica dominante (5) \\
\hline Bibliométrico/Metodológico \\
\hline Bibliométrico (5); Metodológico (6) \\
\hline Gerenciamento \\
\hline $\begin{array}{l}\text { Políticas internas (2); Inovação (4); Estrutura Organizacional (1); Marketing interno (2); Estudo-gerente (1); } \\
\text { Diagnóstico mercadológico (1); Eficiência (1); Tecnologia (2); Antecedentes (local, estabilidade, controlabilidade) (3); } \\
\text { Treinamento (1); Valores culturais/Cross-Cultural (5); Comprometimento da direção (1); Conjunto consideração (2); } \\
\text { Propaganda (1); Conflitos internos (1); Lucratividade (2); Desempenho/Performance/ Estratégia (9); Desconfirmação/ } \\
\text { desconformidade (3); Preço (3); Garantia (1); ECR (Efficient Consumer Response) (1); Flexibilidade (1) }\end{array}$ \\
\hline
\end{tabular}




\section{Análise quantitativa}

Dos 499 autores que participaram da produção dos artigos, treze destacam-se devido ao maior volume de produção nos periódicos e eventos pesquisados. São eles: Gabriel Sperandio Milan (10); Cristiane Pizzutti dos Santos (7); José Luis Felício dos Santos de Carvalho (7); Márcio de Oliveira Mota (7); Danielle Miranda de Oliveira Arruda Gomes (6); Deonir De Toni (6); Fernando Bins Luce (6); Salomão Alencar de Farias (6); Ana Augusta Ferreira de Freitas (5); Daniel Von der Heyde Fernandes (5); Guilherme Trez (5); Ramon Silva Leite (5e Vinícius Sittoni Brasil (5).

Quanto aos setores de serviço estudados, o setor bancário aparece como o mais pesquisado (25), seguido pelas áreas de educação (19), saúde (14), varejo (12), hotelaria (12), telefonia (10), alimentação (9), aéreo (5), academia (5), automobilístico (4) e restaurante fast-food (3). Embora se possa ressaltar que houve uma grande quantidade de áreas pesquisadas, na grande maioria dos casos cada setor foi estudado somente uma ou duas vezes. Já no que concerne à produção científica nos eventos EnANPAD e EMA, a Figura 1 apresenta as publicações ano a ano de cada encontro.

Figura 1 - Produção científica em marketing de serviços no Brasil

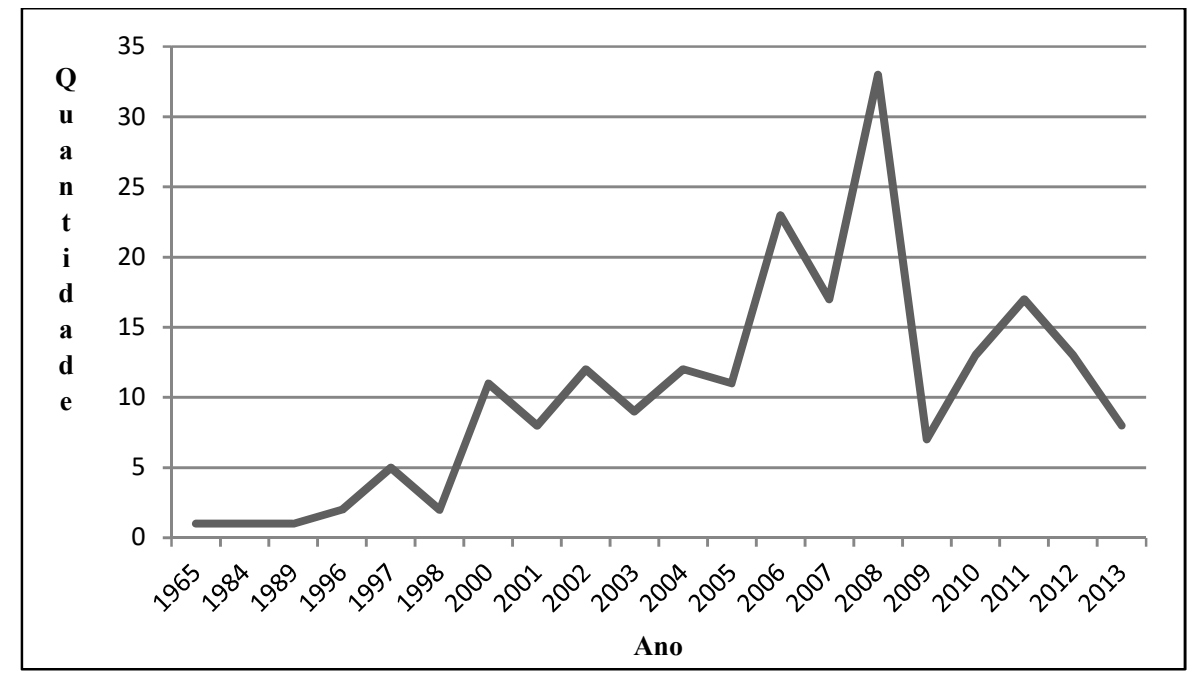

Fonte: elaborada pelos autores.

Como é possível visualizar, os anos de 2006 e 2008 apresentaram a maior quantidade de trabalhos produzidos. Contudo, o declínio no número de estudos realizados nos últimos anos foi considerável, chegando ao menor patamar de produção desde 2000.

Quanto aos autores mais citados nos artigos da área de marketing de serviços pelo Brasil, como é possível observar na Tabela 1, destacam-se: Zeithaml, com 339 citações; Berry, com 321 citações; e Parasuraman, com 298 citações. O autor brasileiro mais citado é a pesquisadora Cristiane Pizzutti dos Santos, com 40 citações e o artigo "Avaliando a qualidade de serviço numa instituição de ensino superior", escrito pelos autores Dutra, Oliveira e Gouveia (2002), é a obra mais citada, com sete citações. 
Tabela 1 - Autores mais citados em marketing de serviços no Brasil

\begin{tabular}{ccc}
\hline Posição & Autor & Total \\
\hline 1 & Zeithaml, V. A. & 339 \\
2 & Berry, L. L. & 321 \\
3 & Parasuraman, A. & 298 \\
4 & Oliver, R. L. & 218 \\
5 & Bitner,M. J. & 150 \\
6 & Grönroos. C. & 122 \\
7 & Kotler, P. & 98 \\
8 & Lovelock, C. H. & 93 \\
9 & Reichheld, F. F. & 62 \\
10 & Wright, L. T. & 50 \\
\hline
\end{tabular}

Fonte: dados da pesquisa.

Quanto às obras mais citadas, visualizadas na Tabela 2, observa-se que os dois principais artigos em periódicos pertencem aos estudos sobre a percepção da qualidade dos serviços. Tais estudos são evidenciados por Berry e Parasuraman (1993) como obras seminais da área de marketing de serviços. Quanto aos principais livros, destacam-se as obras de Oliver que retrata a satisfação de consumidores e de Lovelock e Wright que trata dos conceitos e aplicações do marketing de serviços.

Tabela 2 - Obras mais citadas em marketing de serviços no Brasil

\begin{tabular}{|c|c|c|c|c|c|}
\hline Posição & Obra & Total & Autor & Ano & Publicação \\
\hline 1 & $\begin{array}{l}\text { A conceptual model of service quality and its } \\
\text { implications for the future research. }\end{array}$ & 52 & $\begin{array}{l}\text { Parasuraman, A., Zeithaml, } \\
\text { V. A. e Berry, L. L. }\end{array}$ & 1985 & Periódico \\
\hline 2 & $\begin{array}{l}\text { SERVQUAL: A multiple item scale for } \\
\text { measuring consumer perceptions of service } \\
\text { quality. }\end{array}$ & 50 & $\begin{array}{l}\text { Parasuraman, A., Zeithaml, } \\
\text { V. A. e Berry, L. L. }\end{array}$ & 1988 & Periódico \\
\hline 3 & $\begin{array}{l}\text { Satisfaction: a behavioural perspective on the } \\
\text { consumer. }\end{array}$ & 48 & Oliver, R. L. & 1997 & Livro \\
\hline 4 & Serviços: Marketing e Gestão. & 48 & $\begin{array}{l}\text { Lovelock, C. H. e Wright, L. } \\
\text { Bateson, J. E. G. e }\end{array}$ & 2001 & Livro \\
\hline 5 & Marketing de Serviços. & 35 & $\begin{array}{l}\text { Hoffman, K. D. } \\
\text { Engel, J. F., }\end{array}$ & 2001 & Livro \\
\hline 6 & Comportamento do consumidor. & 32 & $\begin{array}{l}\text { Blackwell, R. D. e Miniard, } \\
\text { P. W. }\end{array}$ & 2000 & Livro \\
\hline 7 & $\begin{array}{l}\text { Measuring service quality: an reexamination } \\
\text { and extension. }\end{array}$ & 30 & Cronin Jr. e Taylor, A. S. & 1992 & Periódico \\
\hline 8 & Whence customer loyalty? & 30 & Oliver, R. L. & 1997 & Periódico \\
\hline 9 & Marketing: Gerenciamento e Serviços. & 29 & Grönroos, C. & 1995 & Livro \\
\hline 10 & $\begin{array}{l}\text { A Cognitive Model of the Antecedents and } \\
\text { Consequences of Satisfaction Decisions. }\end{array}$ & 28 & Oliver, R. L. & 1980 & Periódico \\
\hline
\end{tabular}

Fonte: Dados da pesquisa. 


\section{Análise das propriedades metodológicas}

Analisando os artigos publicados, observa-se que os estudos de tipo quantitativo predominam (115), seguidos por aqueles que se conceituam somente como qualitativos (50), e daqueles cuja tipologia identificase tanto como qualitativa quanto quantitativa (41).

Quanto aos métodos de obtenção de dados, observa-se que a técnica de entrevista foi realizada, de forma geral, como método de extração inicial dos dados para construção de questionários, estando as surveys em predominância quanto aos principais métodos de coleta. Da mesma forma, ressalta-se que a maioria dos estudos se caracteriza como descritivo (113), seguido por trabalhos exploratórios (54), exploratório-descritivos (37) e uma reduzida quantidade de estudos experimentais (2). Observa-se recorrentemente, ademais, a presença de artigos que visam a criação, a validação de escalas ou o desenvolvimento de modelos teóricos com o intuito de explicação de um dado fenômeno, muitos na perspectiva da qualidade; embora se baseiem, geralmente, em estudos estrangeiros para a adaptação de suas escalas ou modelos ao contexto nacional. Quanto aos instrumentos de análise estatística, a modelagem em equações estruturais tem recebido grande atenção, em conjunto com técnicas mais tradicionais como análise fatorial exploratória e análise de variância (ANOVA).

Observou-se, além disto, que a seção reservada à proposição do avanço científico pela sugestão de pesquisas futuras, contidas classicamente na parte final dos trabalhos, refere-se em grande parte a sugestões metodológicas, principalmente no que concerne à aplicação de estudos quantitativos de caráter probabilístico, como resultado de limitações dos estudos de campo.

Cumpre ressaltar ainda que diversos artigos não apresentaram claramente sua categorização metodológica ou a que autores estas classificações se alinham, o que contribuiria para clarificar as correntes metodológicas seguidas. Ainda assim, tais trabalhos foram analisados e agrupados de acordo com as propriedades pertinentes aos estudos realizados.

\section{Análise crítica dos artigos}

Inicialmente, observa-se que apesar das pesquisas terem sido realizadas no setor de serviços, grande quantidade de trabalhos não possui o marketing de serviços como linha teórica dominante. Embora pudessem ter aprofundado estudos para contribuírem formalmente com a área, tais trabalhos valeram-se do setor de serviços, observando minimamente suas particularidades, para demonstrarem conceitos teóricos gerais. Além disso, tais estudos não projetam discussões mais aprofundadas que venham a gerar reflexões teóricas mais relevantes quanto aos aspectos do marketing de serviços propriamente dito, cabendo esta tarefa à inovatividade de pesquisadores internacionais.

Cabe destacar a relação teórica da disciplina de marketing de serviços com as de comportamento do consumidor e, principalmente, o marketing de relacionamento. Observa-se que diversos artigos recorrem aos construtos do marketing de relacionamento como principais unidades de estudo (confiança, lealdade, benefícios relacionais, propaganda boca a boca, comprometimento etc.), embora dediquem seções específicas ao marketing de serviços em seus referenciais teóricos e indiquem como proeminentes os construtos relacionados à disciplina. Ademais, observa-se que há um movimento de miscelânea destas 
teorias dentro do escopo do marketing de serviços devido à profusão de artigos que tratam das temáticas. Tal constatação corrobora considerações de Grove, Fisk e John (2003), que aduzem ser uma união compreensível, uma vez que a construção de relacionamentos seja inerente a qualquer negócio. As contribuições da linha teórica do marketing de relacionamento levantadas nos trabalhos são voltadas, preponderantemente, ao setor de serviços; apesar de muitas vezes não o explicitarem. Cabe, destarte, formalizar essa união.

Observa-se, ademais, uma deficiência conspícua quanto ao posicionamento dos estudos empíricos no que concerne às classificações oferecidas pela literatura. Com efeito, este ponto pode causar certa miopia nos trabalhos desenvolvidos na área. Fica evidente a falta de foco ao se analisar as limitações e sugestões para pesquisas futuras, quando estas existem, pois, em geral, não há propostas de continuidade de uma linha de pesquisa, mas sugestões de realização de estudos em outros setores de serviços a fim de sanar o problema da generalização de resultados; como se todos os serviços fossem iguais. Até mesmo serviços relacionados ao mesmo setor apresentam particularidades que os diferenciam (LOVELOCK, 1983). A inobservância das peculiaridades específicas da área de estudo limita as contribuições de tais trabalhos, fazendo com que exista, inclusive, certa fragilidade na indicação de sugestões para trabalhos futuros.

\section{Revisões e tendências}

Por meio da revisão das tendências relatadas por autores internacionais, Rocha e Silva (2006) apontaram como aprofundamentos em pesquisas no Brasil: a) o melhor entendimento do processo decisório do consumidor com relação a serviços; b) o valor agregado aos produtos com a oferta de serviços; c) a qualidade percebida do consumidor de serviços como antecedente da percepção de valor e satisfação; d) o impacto do ambiente de serviços nas decisões de compra do consumidor; e e) os aspectos negativos do comportamento do consumidor que afetam a decisão de compra como a resistência, o arrependimento, a insatisfação, a rejeição e a ira.

Pôde-se verificar, através da análise, grande volume de estudos relacionados ao item (c), referente aos antecedentes da satisfação e valor percebido como a qualidade percebida, devido à profusão de estudos com o uso da escala SERVQUAL e similares. Outrossim, também houve considerável quantidade de trabalhos relacionados aos itens (a) e (d), porquanto o exame do construto decisão de compra foi realizado em diversos estudos, assim como os fatores relacionados ao ambiente de serviços (vide Quadro 1). Os itens (b) e (e), porém, obtiveram avanços mais tímidos.

Kunz e Hogreve (2011), por sua vez, identificaram os potenciais tópicos de pesquisa na área de marketing de serviços, quais sejam: 1) serviços online e infusão de tecnologia; 2) lógica dominante de serviços e a cocriação do valor; 3) coprodução na alavancagem dos processos dos serviços; 4) gerenciamento da cadeia de valor de serviços; 5) retorno nas decisões do marketing de serviços; 6) gerenciamento da dinâmica das relações com os consumidores; 7 ) análise de retenção e ruptura com os consumidores e; 8) avaliação de reclamações e recuperação de serviços.

Nesta pesquisa observou-se: um predomínio do item (3), referente ao gerenciamento da dinâmica de relações de consumo; desenvolvimento dos primeiros estudos que tratam de serviços online (1); e um número menor de produção referente à lógica dominante de serviços (2). Destaca-se também uma produção 
considerável no que concerne à retenção e ruptura dos consumidores e às falhas e recuperação de serviços, o que abrangeria os itens (7) e (8). Os demais tópicos foram pouco abordados.

$\mathrm{Na}$ tentativa de estabelecimento de novas avenidas de pesquisa, utilizou-se o estudo de Grove, Fisk e John (2003), os quais levantaram tendências à área por meio de um painel com os maiores expoentes do marketing de serviços internacional. Os autores elencaram 38 tendências, sendo algumas aqui adaptadas para o campo de pesquisa nacional, visualizadas no Quadro 2, a seguir. Vale destacar que dentre as tendências apontadas pelos autores, somente as não alcançadas foram citadas no quadro.

\section{Quadro 2 - Tendências ao marketing de serviços no Brasil}

A natureza dos serviços

Analisar o conceito de marketing de serviços, avaliando se o termo não se configura como limitante. Repensar os principais axiomas que distinguem os serviços, como a tangibilidade, a perecibilidade, a inseparabilidade etc.

Pesquisar problemas de maior amplitude, ao invés de focar problemas muito específicos.

\section{O escopo dos serviços}

Enfatizar o marketing de serviços global e local, observando-se as peculiaridades inerentes de cada cultura, realizando-se pesquisas cross-cultural etc.

Investigar o impacto dos serviços sobre o ambiente.

Repensar o papel dos serviços na economia brasileira.

Ampliar as investigações relacionadas às questões sociais.

Examinar problemas reais enfrentados por gestores e empresas de forma geral.

Perquirir o impacto da tecnologia e da internet/e-commerce sobre os serviços.

Examinar a integração entre a gestão de marketing, produção e recursos humanos.

Perscrutar serviços e design de serviços inovadores.

Observar peculiaridades referentes ao contexto brasileiro e o cenário de micro, pequenos e médias empresas.

Serviços e criação de valor

Ampliar as investigações sobre o papel do cliente na produção do serviço.

Examinar o efeito do comportamento do consumidor sobre os empregados.

Perscrutar os afeitos que vão além da qualidade, como a retenção de clientes, lucratividade, participação de mercado etc.

Fonte: Adaptado de Grove, Fisk e Jonh (2003). 


\section{CONSIDERAÇÕES FINAIS}

Este estudo teve como objetivo investigar a produção em marketing de serviços no Brasil. Cumpre ressaltar que os objetivos específicos do estudo foram atingidos, quais sejam: 1) levantar a evolução histórica da subdisciplina no Brasil, através da análise dos principais artigos produzidos, de maneira a erigir o estado da arte do tema no país; 2) identificar as principais categorias teóricas pesquisadas e; 3) levantar tendências de estudo à área com base na produção nacional, observando-se, igualmente, o contexto internacional.

Apesar dos primeiros estudos terem sido realizados a partir da década de 1960, a disciplina de marketing de serviços somente tomou forma no Brasil a partir dos anos 2000. Testemunha-se nesse período maior esforço da academia brasileira para o crescimento do campo de pesquisa; realizado através do estudo de várias searas e setores circunscritos no escopo do marketing de serviços. Não obstante, cumpre salientar que a produção nacional na área apresentou um declínio substancial no último lustro. Quanto aos autores mais citados pela produção científica brasileira, destacam-se os pesquisadores internacionais, o que corrobora a defasagem da produção de caráter original no país.

Ainda que se valham do aporte das teorias da área de marketing de serviços, os achados de diversos artigos pouco retornam a um esforço de teorização que venha a gerar reflexões mais aprofundadas para a área. Nos trabalhos analisados, observa-se o uso reiterado de conceitos advindos de outras áreas do marketing, como comportamento do consumidor e, em especial, do marketing de relacionamento. Devido à profusão de artigos que tratam das temáticas marketing de serviços e marketing de relacionamento, observase um movimento de miscelânea destas disciplinas, uma vez que a articulação entre elas traz certa ampliação do aporte teórico para ambas e, consequentemente, para a área de marketing.

Outros achados dizem respeito a contextos emergentes como os de serviços online ou virtuais. Embora a importância, salientada por Grove, Fisk e Jonh (2003), de se examinar o impacto da tecnologia e da internet/e-commerce sobre os serviços, tais searas dispõem ainda de pouco aporte teórico explicativo para contexto e peculiaridades brasileiras.

Uma observação relevante à academia nacional, ademais, é a importância da criação de revistas específicas para área de marketing. Atualmente, o Brasil detém apenas a Revista Brasileira de Marketing REMark. Em vista da profusão de artigos, seja em eventos, com destaque para o EnANPAD e para o EMA, seja em revistas não especializadas, a sugestão para acadêmicos e instituições se refere à criação de novos espaços, cujo foco teórico seja o marketing. A falta de discussões mais direcionadas pode contribuir para a fragmentação e o declínio da disciplina de marketing de serviços no Brasil, como se observou no último lustro. Ao se analisar o crescimento da disciplina em âmbito internacional, por outro lado, observa-se que o campo foi alavancado pela criação de importantes revistas, que são atualmente referências na explicitação do avanço científico na área.

A criação de novas revistas poderia vir a fomentar pesquisas que contribuiriam, inclusive, para a construção de teorias mais alinhadas com o contexto e peculiaridades nacionais, marcados pela presença de micro, pequenos e médios empresários com necessidades de marketing mais afins com a maneira brasileira de produzir e consumir.

Aponta-se ainda a revisão da produção científica nacional em outras áreas do marketing, com o intuito principal de se observar seus estados da arte, a fim de se levantar tendências gerais. Ademais, sugerir-se-ia 
a comparação dos levantamentos realizados entre as subdisciplinas do marketing para o delineamento da evolução da disciplina.

\section{REFERÊNCIAS}

ABREU, C. B. Serviço pós-venda: a dimensão esquecida do marketing. RAE - Revista de Administração de Empresas, v. 36, n. 3, p. 24-31, 1996.

ARRUDA, M. C. C.; ARRUDA, M. L. A. Satisfação do cliente das companhias aéreas brasileiras. RAE - Revista de Administração de Empresas, v. 38, n. 3, p. 25-33, 1998.

BATESON, J. E. G. Testing a conceptual framework for consumer service marketing. Cambridge, MA: Marketing Science Institute, 1978.

BERRY, L. L.; PARASURAMAN, A. Building a New Academic Field - The Case of Service Marketing. Journal of Retailing, v. 69, n. 1, p. 13-60, 1993.

BITNER, M. J. Servicescapes: The Impact of Physical Surroundings on Customers and Employees. Journal of Marketing, v. 56, n. 2, p. 57-71, 1992.

BOOMS, B. H.; BITNER, M. J. Marketing strategies and organizational structures for service firms. In: DONNELLY, J. H.; GEORGE, W. R. (Eds.) Marketing of Services. Chicago, IL: American Marketing Association, p. 47-51, 1981.

BOWEN, J. Development of a taxonomy of services to gain strategic marketing insights. Journal of the Academy of Marketing Science, v. 18, n. 1, p. 43-49, 1990.

BRASIL, V. S. Sistemas de prestação de serviços: um enfoque no processo de escolha do consumidor. In: ENCONTRO NACIONAL DA ASSOCIAÇÃO NACIONAL DOS PROGRAMAS DE PÓS-GRADUAÇÃO E PESQUISA EM ADMINISTRAÇÃO, 26., 2002, Salvador. Anais... Salvador: ANPAD, 2002.

BREI, V. A. Construção da confiança em trocas relacionais de serviço: uma pesquisa nacional com usuários de internet. In: ENCONTRO NACIONAL DA ASSOCIAÇÃO NACIONAL DOS PROGRAMAS DE PÓS-GRADUAÇÃO E PESQUISA EM ADMINISTRAÇÃO, 27, 2003, Atibaia. Anais... Atibaia: ANPAD, 2003.

CASTRO, D. F. L.; SILVEIRA-MARTINS, E.; DELUCA, M. A. M.; ROSSETTO, C. R. Qualidade de serviço: um estudo bibliométrico nas bases de dados internacionais. In: ENCONTRO NACIONAL DA ASSOCIAÇÃO NACIONAL DOS PROGRAMAS DE PÓS-GRADUAÇÃO E PESQUISA EM ADMINISTRAÇÃO, 37, 2013, Rio de Janeiro. Anais... Rio de Janeiro: ANPAD, 2013.

CRONIN, J. R. J. Looking back to see forward in services marketing: some ideas to consider. Managing Service Quality, v. 13 , n. 5 , p. $332-337,2003$.

DIAS, S. L. F. G. Fronteiras e controvérsias do conhecimento em marketing: existe uma nova lógica dominante? In: ENCONTRO NACIONAL DA ASSOCIAÇÃO NACIONAL DOS PROGRAMAS DE PÓS-GRADUAÇÃO E PESQUISA EM ADMINISTRAÇÃO, 30, 2006, Salvador. Anais... Salvador: ANPAD, 2006.

DUTRA, H. F. O.; OLIVEIRA, P. A. S.; GOUVEIA, T. B. Avaliando a qualidade de serviço numa instituição de ensino superior. In: ENCONTRO NACIONAL DA ASSOCIAÇÃO NACIONAL DOS PROGRAMAS DE PÓS-GRADUAÇÃO E PESQUISA EM ADMINISTRAÇÃO, 26, 2002, Salvador. Anais... Salvador: ANPAD, 2002.

FIGUEIREDO, K. F. Coexistência entre produção e marketing em empresas de serviços: algumas evidências empíricas. RAUSP - Revista de Administração da Universidade de São Paulo, v. 24, n. 3, p.11-20, 1989.

GIL, A. C. Métodos e técnicas de pesquisa social. 3. ed. São Paulo: Editora Atlas, 1989. 206 p.

GODOI, C. K.; BALSINI, C. P. V. A pesquisa qualitativa nos estudos organizacionais brasileiros: uma análise bibliométrica. In: GODOI, C. K.; BANDEIRA-DE-MELO, R.; SILVA, A. B. (Orgs) Pesquisa Qualitativa em estudos organizacionais: Paradigmas, estratégias e métodos. São Paulo: Saraiva, p. 89-113. 2006.

GROVE, S. J.; FISK, R. P. The service experience as a theater. Advances in Consumer Research, v. 19, p. 455-461, 1992.

GROVE, S. J.; FISK, R. P.; JOHN, J. The Future of Services marketing: forecasts from ten services experts. Journal of Services Marketing, v. 17, n. 2, p. 107-121, 2003.

GUMMESSON, E.; GRÖNROOS, C. The emergence of the new service marketing: Nordic school perspectives. Journal of Service Management, v. 23, n. 4, p. 479-497, 2012.

KUNZ, W. H.; HOGREVE, J. Toward a deeper understanding of service marketing: the past, the present, and the future. International Journal of Research in Marketing, v. 28, n. 3, p. 231-247, 2011.

LIMA FILHO, A. O. L. Possibilidades do mercado de serviços no Brasil. RAE - Revista de Administração de Empresas, v. 5 , n. 16, p. $95-115,1965$. 
LOVELOCK, C. H. Classifying services to gain strategic Marketing insights. Journal of Marketing, v. 47, n. 3, p. 9-20, 1983.

MONDO, T. S.; FIATES, G. G. S. Os Modelos de Qualidade em Serviços: Mapeamento da Produção Científica de Alto Impacto para a Área de Administração no Brasil até 2012, motivo de preocupação para os pesquisadores de Marketing? In: ENCONTRO NACIONAL DA ASSOCIAÇÃO NACIONAL DOS PROGRAMAS DE PÓS-GRADUAÇÃO E PESQUISA EM ADMINISTRAÇÃO, 37, 2013, Rio de Janeiro. Anais... Rio de Janeiro: ANPAD, 2013.

PARASURAMAN, A.; ZEITHAML V. A.; BERRY, L. L. A conceptual model of service quality and its implication for future research. Journal of Marketing, v. 49, n. 4, p. 41-50, 1985.

PARASURAMAN, A.; ZEITHAML V. A.; BERRY, L. L. Servqual: A multiple-item scale for measuring consumer perceptions of service quality. Journal of Retailing, v. 64, n. 1, p. 12-40, 1988.

PARASURAMAN, A.; ZEITHAML V. A.; MALHOTRA, A. E-S-QUAL: A multiple-item scale for assessing electronic service quality. Journal of Service Research, v. 7, n. 3, p. 213-133, 2005.

ROCHA, A.; SILVA, J. F. Marketing de Serviços: Retrospectivas e Tendências. RAE - Clássicos, v. 46, n. 4, p. 79-87, 2006.

RODRIGUES, S. B.; BARBOSA, F. V.; LUZ, T. R. D.; KILIMNIK, Z. M. Microeletrônica e organização do trabalho no setor de serviços. RAUSP - Revista de Administração da Universidade de São Paulo, v. 19, n. 4, p. 25-37, 1984.

SHOSTACK, G. L. Breaking free from product marketing. Journal of Marketing, v. 41, n. 2, p. 73-80, 1977.

URDAN, A. T. A relação entre qualidade de marketing e qualidade percebida no modelo de lacunas de qualidade de serviços. In: ENCONTRO NACIONAL DA ASSOCIAÇÃO NACIONAL DOS PROGRAMAS DE PÓS-GRADUAÇÃO E PESQUISA EM ADMINISTRAÇÃO, 21, 1997, Rio das Pedras. Anais... Rio das Pedras: ANPAD, 1997.

VARGO, S. L.; LUSCH, R. Evolving to a New Dominant Logic for Marketing. Journal of Marketing, v. 68, n. 1, p. 1-17, 2004.

VEIGA, R. T.; GONÇALVES, C. A.; MOURA, A. I. Um exame empírico do modelo de consequências comportamentais da qualidade de serviços. In: ENCONTRO NACIONAL DA ASSOCIAÇÃO NACIONAL DOS PROGRAMAS DE PÓSGRADUAÇÃO E PESQUISA EM ADMINISTRAÇÃO, 26, 2002, Salvador. Anais... Salvador: ANPAD, 2002.

VIEIRA, V. A. Mensuração da qualidade de serviço no varejo eletrônico e seu impacto sobre as intenções comportamentais. In: ENCONTRO NACIONAL DA ASSOCIAÇÃO NACIONAL DOS PROGRAMAS DE PÓSGRADUAÇÃO E PESQUISA EM ADMINISTRAÇÃO, 34, 2010, Rio de Janeiro. Anais... Rio de Janeiro: ANPAD, 2010.

VILLAS, M. V.; MACEDO-SOARES, T. D. L.; RUSSO, G. M. Bibliographical Research Method for Business Administration Studies: a Model Based on Scientific Journal Ranking. Brazilian Administration Review, v. 5, n. 2, p. 139159, 2008. 